\title{
Los enemigos íntimos de la democracia Tzvetan Todorov
}

\author{
Galaxia Gutenberg, Barcelona, 2012, 208 págs.
}

Fernando de la Cuadra

Red Universitaria de Investigadores sobre América Latina.

Email: fmdelacuadra@gmail.com

En fecha reciente el jugador Josy Altidore fue víctima de insultos racistas en el Campeonato Holandés. Cada vez que tocaba la pelota, los hinchas del equipo contrario comenzaban a imitar un mono. La respuesta del jugador a estas manifestaciones de hostilidad y racismo fue la siguiente:

“¿Qué se puede hacer? Apenas espero que esos hinchas encuentren un medio de mejorar (como personas). Uno solo pude rezar por ellas. Yo siento como si tuviese una obligación con mi club y mi familia, de no reaccionar a cosas como esa y mostrar que el club es mejor que eso y que fui muy bien educado para responder a un comportamiento tan ridículo. Nosotros deberíamos esperar que la humanidad pudiese crecer, pero eso aún está vivo, el racismo. Todo lo que podemos hacer ahora es educarnos y educar a los niños para que ellos sean mejores que eso. Yo no voy a combatirlos (los hinchas racistas). Ellos tienen sus problemas y necesitan de ayuda. Vamos a rezar por ellos y esperar que mejoren en el futuro."”

La declaración de Altidore nos sitúa al centro de una de las tesis levantadas por Tzvetan Todorov en su libro: el racismo. En el breve e incisivo ensayo, este filólogo, historiador de las ideas e intelectual búlgaro radicado en Francia, expone con proverbial claridad sobre cuales serian los principales riesgos que enfrentan las democracias en el mundo contemporáneo, a saber, el mesianismo, el ultraliberalismo y el populismo.

Lo más asustador de este peligro es que proviene de la propia esfera democrática, cuando los valores y mecanismos mutuamente compartidos adquieren una "desmesura" (hybris), o sea, un uso excesivo y distorsionado de tales valores. Esto resulta cuando los ideales de la vida democrática como progreso, libertad o pueblo son absolutizados a tal punto que se transforman en elementos de coerción de las sociedades y los individuos. En palabras de Todorov: "El pueblo, la libertad, el progreso son elementos constitutivos de la democracia; pero si uno de ellos rompe su vínculo con los demás, escapando a todo intento de limitación y se erige en principio único y absoluto, esos elementos se convierten en peligros: populismo, 
ultraliberalismo y mesianismo, los enemigos íntimos de la democracia.” (Todorov, op. cit.: 13).

En el inicio de su libro, Todorov intenta demostrar que a diferencia de lo que es difundido permanentemente por los políticos, experts y mass media en general, el islamismo integrista y los grupos terroristas jihadistas (como a Al-Qaeda) no representan una amenaza significativa para las democracias occidentales si comparadas con aquellas formas totalitarias ocurridas durante el siglo XX, tales como el comunismo o el nazifascismo. Aquella es una perspectiva errada, construida intencionalmente para ocultar los verdaderos riesgos que enfrentamos en los días actuales, pues el peligro realmente imperante consiste en las nefastas fuerzas internas que la propia democracia produce y, de esta manera, combatirlas y neutralizarlas es bastante más difícil, en la medida que ellas invocan el espíritu democrático cuando en realidad se encuentran corroyendo sus mismos pilares. Como decía Blaise Pascal "Nunca se hizo tan perfectamente el mal como cuando fue de buena voluntad”, es el Mal surgiendo del Bien.

En la historia humana la búsqueda del Bien frecuentemente se irguió a partir del convencimiento de que los otros precisan de ayuda y "salvación”, razón por la cual me transformo en la encarnación de la misión de construir la redención universal. ${ }^{2}$ Este mesianismo se expresó en diversos momentos históricos -en las guerras revolucionarias y coloniales, así como en el proyecto comunista-, pero en la forma contemporánea él se viste con los ropajes de los valores democráticos universales, cuando no son simplemente deseos de poder y riqueza travestidos de humanismo.

Así, surge en primer lugar el llamado “derecho de injerencia”, es decir, si en un determinado país se realizan violaciones a los derechos humanos, otros países pueden decidir utilizar su poderío para evitar que ditas violaciones se continúen consumando (Kosovo). Otra modalidad de este nuevo mesianismo ha sido acuñada con el nombre de "guerra contra el terrorismo” en que se torna valida e imprescindible la ocupación de un determinado país en el caso de que este sea utilizado como base de operaciones de grupos terroristas (Afganistán). Por su vez, la guerra preventiva considera legítima la utilización de la fuerza para liberar al conjunto de la humanidad de algún peligro inminente. Finalmente, existe la formula de la denominada "guerra humanitaria”, en que también se produce la imposición por la fuerza a otros países o naciones de los valores universales, utilizando para ello intervenciones militares con ocupación territorial, como ha sido evidente en los casos de Irak o de Libia.

De hecho, el concepto de guerra humanitaria representa una contradicción flagrante, debido a que difícilmente se puede pensar que las acciones decurrentes de una guerra puedan traer algo de humanidad en su seno. No obstante, lo que es factible de apreciar por detrás todos estos conceptos es que la gran mayoría de las intervenciones ha sido motivada por razones de orgullo y de poder y que su justificación aduciendo pretextos humanitarios representa un tipo de mesianismo interesado que regularmente provo- 
ca más daños que beneficios para los pueblos que se pretende proteger. Efectivamente, el resultado de estos “emprendimientos” solamente condujo a un aumento de los desastres da guerra con sus enormes secuelas de víctimas inocentes.

La otra forma que la democracia posee para convertirse en su propia enemiga, se relaciona con la pérdida del equilibrio que debería existir entre el poder consagrado al pueblo y la libertad de los individuos. En este caso, el vínculo que se establece entre la soberanía popular y la autonomía de la persona -nos advierte Todorov- necesita tener una limitación mutua en la cual "el individuo no debe imponer su voluntad a la comunidad, y ésta no debe inmiscuirse en los asuntos privados de sus ciudadanos.” (Todorov, op. cit.: 12).

La oposición entre populismo y ultraliberalismo nos convoca entonces a pensar sobre los límites que es indispensable establecer para que ambas dimensiones se mantengan en equilibrio, aún cuando, parafraseando a Norbert Elias, esto se dé a través de un “equilibrio móvil de tensiones”. Siempre existe el peligro de que la consagración de lo popular pueda transformarse en la encarnación del bien colectivo y, consecuentemente, alimentar la idea de que ciertos valores como la patria, la nación, la raza o la comunidad, deben ser compartidos por la totalidad de los seres humanos. Si el equilibrio es inestable, ello implica que se puede transitar fácilmente para expresiones de autoritarismo, xenofobia, racismo e intolerancia a la diversidad, cuando lo diferente es rechazado por constituir una amenaza a la esencia de determinado pueblo.

Generalmente este populismo se presenta bajo la forma de demagogia, prometiendo dar soluciones fáciles a problemas complejos sin existir ninguna certeza de que las podrá cumplir. El populismo representa una política de corto plazo que se limita a proponer salidas tangibles a una audiencia masiva ávida de respuestas - comúnmente a través de un contacto directo en espacios públicos - y cuyos miedos son exacerbados. En la experiencia reciente, el populismo europeo viene atacando el multiculturalismo argumentando que él encarna un serio peligro para la identidad nacional. ${ }^{3}$

De esta manera, el populismo hipertrofiado impide reconocer la humanidad de los otros y disemina la intolerancia de aquello que es diferente. Por eso la democracia corre un grave riesgo cuando es substituida por el populismo, "que pasa por alto la diversidad interna de la sociedad y la necesidad de plantearse las necesidades del país a largo plazo, más allá de las satisfacciones inmediatas.” (Todorov, op. cit.: 184).

Inversamente, en el conflicto con el populismo y sus formas autoritarias, la hipervalorización de los individuos puede acarrear el desprecio por todo aquello que reconoce lo colectivo. Siendo así, la libertad individual y la voluntad del individuo se superpone a cualquier intento de construir el bienestar general, en que finalmente las personas son movidas por 
un repertorio de preferencias individuales, especialmente económicas, viéndose aisladas unas de las otras y desechando la importancia del tejido social. Sabemos por toda la tradición sociológica que la sociedad no se resume a la mera suma de los individuos que son parte de ella, al contrario, ella es un producto de las interacciones precedentes y constantes que se establecen entre sus miembros.

Siendo la libertad individual un aspecto fundamental de la democracia, ésta puede también constituirse en una amenaza cuando se escinde del todo social, cuando consagra la voluntad de los individuos por sobre el resto de la colectividad, cuando adquiere un poder ilimitado por encima de la voluntad general. En el intento por libertar a las personas de las ataduras y de la subordinación del Estado, el ultraliberalismo abandona a los individuos a la suerte del mercado y las empresas. Oponiéndose a toda medida de regulación por parte de los poderes públicos, el ultraliberalismo deja la humanidad huérfana de protección, entregada al libre juego de la oferta y la demanda, de los mercaderes, de los financistas y de los poderosos.

Estamos finalmente ante la presencia de una tríada (mesianismo, populismo, ultraliberalismo) que va corroyendo los fundamentos de la propia promesa democrática, de modo que los principios esenciales del discurso democrático se transforman en amenazas concretas: "la libertad pasa a ser tiranía, el pueblo se transforma en masa manipulable, y el deseo de defender el progreso se convierte en espíritu de cruzada. La economía, el Estado y el derecho dejan de ser los medios para el desarrollo de todos y forman parte ahora de un proceso de deshumanización.” (Todorov, op. cit.: 186).

¿Qué podemos hacer para superar este escenario aparentemente irreversible? Pienso que Todorov concordaría con el tenor del discurso de Josy Altidore citado en el inicio. Quizás si una respuesta semejante pueda ser buscada en las palabras finales del autor, cuando señala que un remedio para nuestros males contemporáneos debería consistir en una evolución de las mentalidades que permita "recuperar el entusiasmo del proyecto democrático" e intentar construir un mejor equilibrio entre sus principios fundamentales, progreso, pueblo y libertad.

Nelson Mandela acostumbraba decir que, así como la esclavitud y el apartheid, la pobreza no es un accidente. Ella es una creación del hombre y puede ser eliminada con las acciones dos seres humanos. Tal vez las aspiraciones y esperanzas de Todorov pasen lejos de los desafíos que tenemos por delante, pero su diagnóstico de las sociedades modernas y su apelo incontestable a la potencia de la voluntad humana sean un primer intento válido de avanzar en el esfuerzo colectivo para hacer del mundo un espacio de convivencia más plural, afectuoso y fraterno. 


\section{Notas}

${ }^{1}$ Allan Caldas, “Racismo interrompe jogo na Copa da Holanda”, O Globo, 29/01/2013.

${ }^{2}$ Las referencias teológicas se deben precisamente al carácter misionero de la empresa, que como todo acto religioso se incumbe de un profundo voluntarismo y fe derivada de la Gracia Divina, aspectos que el autor recupera en el debate entre Pelagio y San Agustín respecto de la dualidad entre la voluntad humana y la predestinación divina.

${ }^{3}$ La consecuencia más dramática de esta ideología son los asesinatos en serie cometidos en Noruega en donde un nacionalista fanático mató a 84 personas en nombre de una supuesta protección o resguardo de la identidad cultural tradicional. 